Shaun Sellars continues this exciting and essential series on ethical dilemmas in dentistry which appears in every second issue of the $B D J$.

Few of us can be unaware of the legal case of 'Montgomery v Lanarkshire Health Board.' This 2015 case has affected us all, by redefining the legal expectations for consent in healthcare. Much has been written about how we now have onerous or impossible expectations when it comes to gaining consent for treatment, specifically involving having to explain a multitude of risks of treatment to our patients. How much of this is true, and how much is hyperbole?

To consider the effect of 'Montgomery', we should first look at what it replaced. The Bolam test originated in 1957 and states that if a doctor (or dentist) reaches the standard which a reasonable body of practitioners would agree with then they are not to be found negligent. This was tested in the 1985 Sidaway case in relation to consent. Here it was judged that it was for the practitioner to judge what risks to disclose. The test is what a reasonable practitioner would consider significant, no matter whom the patient.

Stop and think about this for a while. Before Montgomery, it would be perfectly legally acceptable to have a straightforward cookie-cutter consent process for every patient. While that may sound attractive, surely we owe patients more than this? As healthcare practitioners, should we not be tailoring every aspect of the treatment of our patients to that specific patient sitting in front of us? And shouldn't that include how we gain their consent for that treatment?

To do this means that we need to get to know our patients, appreciate what matters to them specifically and ask the right questions to elicit the right information. We may know what the common and rare risks (and benefits) of treatment may be, but without understanding our patients, then how are we to relate these to them?

There is another side to this. The GDC guidelines on consent already stated that practitioners must consider all relevant treatment options. They also mention that dentists should make efforts to find out what patients want to know, in addition to what the practitioner feels ought to be disclosed with regard to risks. These guidelines date from well before the Montgomery ruling. Ethically, this makes complete sense. For example, if your livelihood is dependent on your singing ability, then it's quite likely

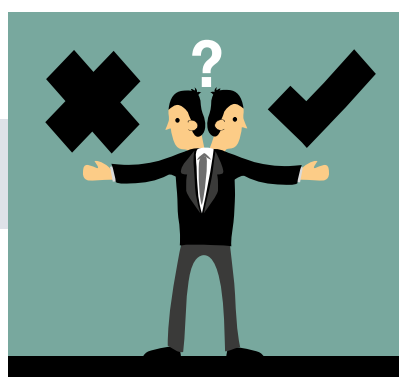

you're more concerned about nerve damage following wisdom tooth extractions than the average patient.

In fact, even back in the Sidaway case, Lord Scarman argued against the Bolam test. He suggested, just like in the Montgomery ruling, that the practitioner has a duty to inform the patient of the inherent and material risks of any treatment. Lord Scarman's words may not have persuaded the remainder of the judges in that case, but they were certainly an influence on those sitting on Montgomery.

It is certainly true that Montgomery changed the legal viewpoint with regards to valid consent. It could be argued, quite strongly, that from an ethical standpoint, Montgomery did very little, if anything at all. We should always be treating the patient in our surgery as an individual, throughout the treatment process, and gaining valid consent is just another part of this. The Montgomery ruling simply altered the law to be in line with our existing ethical duties.

\title{
Around a quarter of Scots say dental treatment is unaffordable
}

Almost a quarter (23\%) of Scottish people say they would like to have the recommended levels of dental treatment but cannot afford to, according to a recent survey carried out by YouGov for Citizens Advice Scotland (CAS).

The organisation's survey, details of which were released on 26 April 2019, included responses from more than 2,000 people aged 18 and older and revealed the extent of financial hardship being experienced amongst the nation.

The survey also found that $25 \%$ of respondents said they found it 'difficult' or 'very difficult' to cope on their present income, while $30 \%$ would like to put by at least $£ 20$ per month for a 'rainy day', but could not afford to.

A quarter said they would like to save regularly for a pension but, again, were unable to financially and $28 \%$ said they could not afford to keep their homes decorated in a decent condition.

The survey also asked Scottish workers how often they ran out of money altogether before payday, meaning that they had to use their credit, overdraft facilities or borrow money to get by.

A quarter said 'most of the time' or 'always', and a further $22 \%$ said 'sometimes'.

When asked how this made them feel, $71 \%$ of that group said 'stressed', $62 \%$ said 'anxious' and $42 \%$ said 'embarrassed' amongst other responses.
CAS Chief Executive Derek Mitchell said: 'Advisers in Citizens Advice Bureaux across Scotland deal every day with people who are in financial difficulty, so we are no strangers to the problems people are experiencing. However, it is

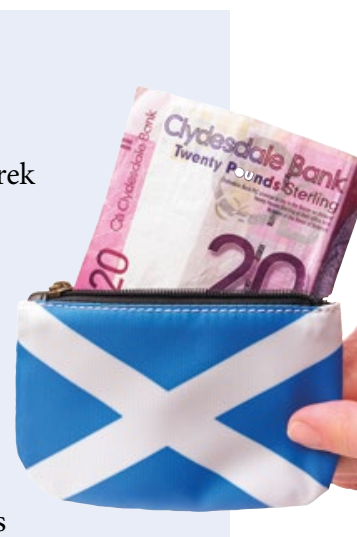
a shock to see the extent of these problems in the population as a whole.

'It's clear from these figures that too many families in Scotland are simply not able to cope on their current income. And even those who are managing are only one financial shock away from falling below the line.' 